\title{
Intriguing Variations of Dorsalis Pedis Artery with Clinical Correlations
}

\author{
P. J. Barot ${ }^{1}$, P. R. Koyani ${ }^{2 *}$ \\ ${ }^{1}$ Tutor, Department of Anatomy, P. D. U. Medical College, Rajkot, Gujarat, India \\ ${ }^{2}$ Assistant Professor, Department of Anatomy, P. D. U. Medical College, Rajkot, Gujarat, India
}

DOI: 10.36348/SIJAP.2019.v02i12.001

| Received: 24.11.2019 | Accepted: 04.12.2019 | Published: 06.12.2019

*Corresponding author: P. R. Koyani

\section{Abstract}

Objective: Dorsalis pedis artery represents the continuation of anterior tibial artery distal to level of ankle joint. The dorsalis pedis angiosome encompasses the entire dorsal aspect of foot through its branches eg. Medial tarsal, Lateral tarsal, Arcuate and 1st dorsal metatarsal arteries. Dorsalis pedis artery variation have been reported in past. Evaluation of dorsalis pedis artery pulsation is useful clinical test for assessing peripheral arterial diseases. Dorsalis pedis artery is the main source of blood supply to foot. Knowledge about origins, course, distribution and branching pattern is important for angiographers, vascular surgeons and reconstructive surgeons who operate upon these region. Method: Study of dorsalis pedis artery was done in forty dissected lower limbs of unknown sex and age from department of anatomy, PDUMC, RAJKOT. Result: In our study normal course and branching pattern of dorsalis pedis artery was found in $87.5 \%$ cases. Variation in branching pattern of dorsalis pedis artery was found in $12.5 \%$ cases. Conclusion: Variable branching pattern of dorsalis pedis artery is common. Therefore, a thorough knowledge of anatomy of dorsalis pedis artery is of prime importance to Radiologists, Surgeons and Anatomist.

Keywords: Dorsalis pedis artery, Branching pattern, Arcuate artery, Peripheral vascular disease, Myocutaneous flaps.

Copyright @ 2019: This is an open-access article distributed under the terms of the Creative Commons Attribution license which permits unrestricted use, distribution, and reproduction in any medium for non-commercial use (NonCommercial, or CC-BY-NC) provided the original author and source are credited.

\section{INTRODUCTION}

Angiosomes are three dimensional anatomical territories supplied by source arteries and accompanying veins and are composed of skin, underlying fascia, muscles and bones. They may be further classified into arteriosomes and venosomes [1].

These angiosomes are used for raising viable pedicle flaps for successful tissues reconstruction in lacerated wounds in road traffic accidents/bomb blast injuries, diabetic neuropathy causing skin ulcers and ruptures of tendo-achilis, non-healing venous ulcers in thalessaemia/varicose veins, 3rd degree burn injuries [2].

Arteria dorsalis pedis is the chief irrigating vessel of the dorsum of the foot. Examination of pedal pulse remains useful clinical tool while evaluating peripheral circulation [3]. The dorsum of the foot is supplied by the dorsalis pedis artery. Dorsalis pedis artery is the continuation of anterior tibial artery below the ankle joint. It runs along the tibial side of the dorsum of the foot upto the proximal part of the first intermetatarsal space. At this point it turns into the sole between the two heads of the first dorsal interosseous muscle and completes the plantar arch. At the junction with the plantar arch it gives first plantar metatarsal artery $[1,4]$.

The branching pattern of the arteria dorsalis pedis as mentioned in the classical textbook description is arcuate artery, medial and lateral tarsal arteries and first dorsal metatarsal artery $[5,6]$. The dorsalis pedis artery and its first dorsal metatarsal branch give rise to small direct cutaneous branches that supply the dorsal foot skin between the extensor retinaculum and the first web space.

This vessel provides the basis for a fasciocutaneous flap raised from this region, and which may be used to cover superficial defects elsewhere.

\section{MATERIALS AND METHODS}

Study was carried out on 40 formalin fixed lower extremities, in the department of anatomy, P. D. U. Medical College, Rajkot, Gujarat, India. This study was performed during routine dissection classes of $1 \mathrm{st}$ MBBS, over a period of 2 years.

These lower limbs were dissected carefully to explore the dorsalis pedis artery, and its branches were traced, observed, noted and photographed. 
The dorsalis pedis artery was traced from its origin in the mid-malleolar region to its termination at the proximal end of the first metatarsal space, the long extensor tendons were severed. Dorsalis pedis artery was identified and the origin, branching pattern and course were noted.

\section{OBSERVATIONS AND RESULTS NORMAL COURSE AND BRANCHES OF DORSALIS PEDIS ARTERY}

In present study $87.5 \%$ of cases, anterior tibial artery continued as the dorsalis pedis artery and gave the lateral tarsal artery and medial tarsal artery, arcuate artery and first dorsal metatarsal artery and continued as the deep plantar artery after piercing the first dorsal interosseous muscle.

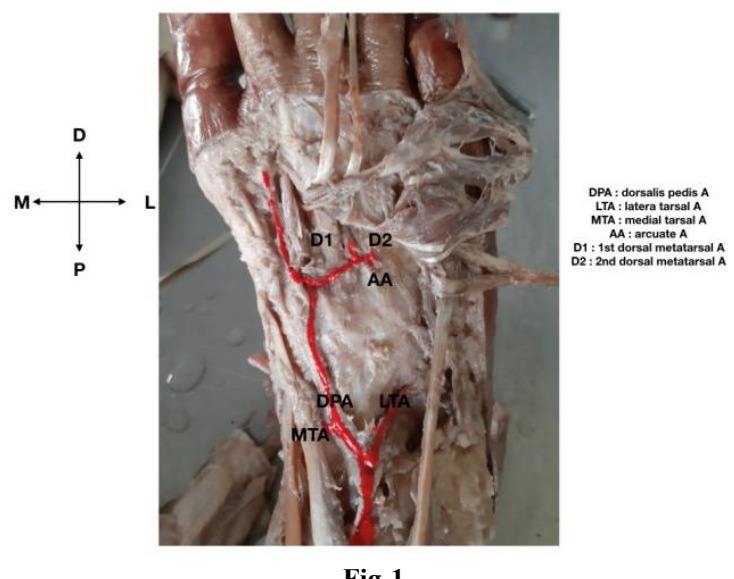

Fig-1

\section{THE DORSALIS PEDIS ARTERY WAS ABSENT}

In $2.5 \%$ specimen the dorsalis pedis artery was absent. Here anterior tibial artery bifurcated into two terminal branches, medial and lateral tarsal arteries, in front of ankle joint (here the calibre of the artery is very small). Here dorsalis pedis artery and first dorsal metatarsal arteries were completely absent. 2nd, 3rd and 4th dorsal metatarsal arteries came from lateral tarsal artery.
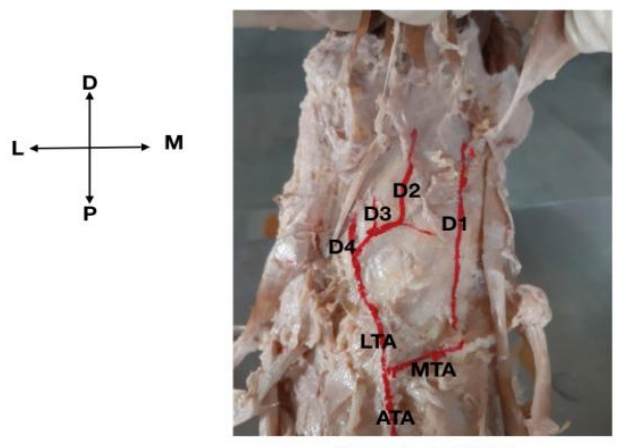

$$
\begin{aligned}
& \text { ATA : anterior tibial A } \\
& \text { MTA : media tarsal A } \\
& \text { LTA : lateral tarsal A } \\
& \text { D1 : 1st dorsal metatarsal A } \\
& \text { D2 : 2nd dorsal metatarsal A } \\
& \text { D3 : 3rd dorsal metatarsal A } \\
& \text { D4 : 4th dorsal metatarsal A }
\end{aligned}
$$

Fig-2

\section{ABSENCE OF ARCUATE ARTERY}

In $10 \%$ cases dorsalis pedis artery began as continuation as anterior tibial artery and coursed to the first interosseous space. In its course, it has provided lateral and medial tarsal arteries.Dorsalis pedis artery before piercing $1 \mathrm{st}$ dorsal interosseous muscle, provided 1st dorsal metatarsal artery. Arcuate artery were completely absent. 2nd, 3rd and 4th dorsal metatarsal artery arises from lateral tarsal artery.

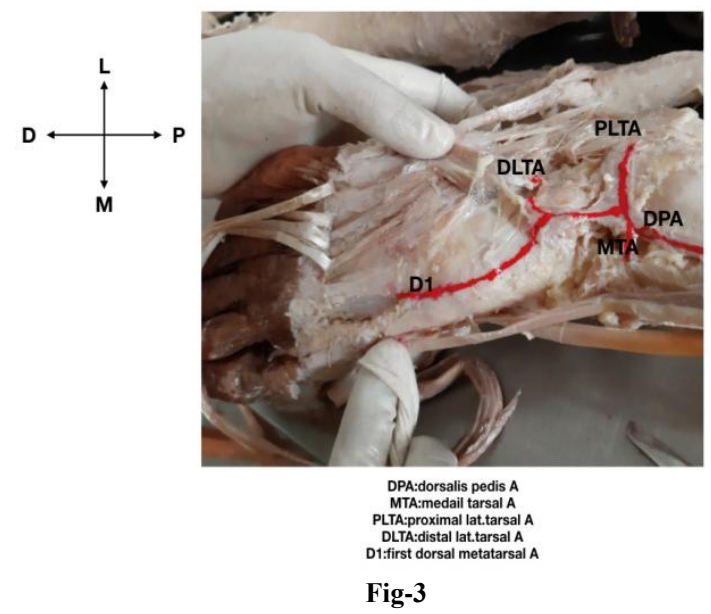

\section{DISCUSSION}

The Dorsalis pedis artery is a main blood vessel of lower limb that carries oxygenated blood to the dorsal surface of foot. It arises out at anterior aspect of ankle joint. It is a continuation of anterior tibial artery at mid-malleolar point. It terminates at proximal part of first metatarsal space where it divides into first dorsal metatarsal artery and deep plantar artery which ends by forming deep plantar arterial arch [7]. Variation in the blood vessels and their abnormal course can be attributed to their development. Small blood vessels (which are derived from blood island in third or fourth week of development) unite and form a continuous network from which buds grow out later, these buds canalised and form new vessels.

Depending on the functional dominance some vessels degenerate and the diverge in the mode of origin and course of principal vessels [9].

Vengadesan B et al., [11] reported that dorsalis pedis artery was replaced by perforating branch of peroneal artery in 5\%, Mestadagh $\mathrm{H}$. B. Observed same in $12 \%$ and Bailleul J. P [13] Observed $8 \%$ of cases. In the present study it was not observed that the dorsalis pedis artery is replaced by the perforating branch of peroneal artery.

Kesavi D., Keerti Singh et al., [14] noticed higher bifurcation of anterior tibial artery. In the present study dorsalis pedis artery begins in the front of ankle between two malleolli in all specimen, except $2.5 \%$ cases. 
Nilesh K Mitra et al., [16] Reported 14.29\% cases in which 2 nd dorsal metatarsal artery originating from dorsalis pedis artery. In the present study it was observed the the 2nd dorsal metatarsal artery arises from lateral metatarsal artery in $10 \%$ cases.

In $87.5 \%$ of cases anterior tibial artery continued as dorsalis pedis artery and had its course and branches as classical textbook description. M S Rajeshwari et al., [7] reported $54.76 \%$ cases of normal dorsalis pedis artery and $9.52 \%$ cases in which anterior tibial artery bifurcated as medial tarsal artery and lateral tarsal artery. Int the present study $2.5 \%$ cases observed as anterior tibial artery bifurcated into medial tarsal artery and lateral tarsal artery with complete absence of dorsalis pedis artery. Yamada et al., [10] reported absence of dorsalis pedis artery $6.7 \%$ cases where dorsal metatarsal arteries were supplied by plantar arteries.

Table-1: Comparison of branching pattern of dorsalis pedis artery in our study with other authors is shown

\begin{tabular}{|l|l|l|l|l|}
\hline PARAMETER & VIJAYALAKSHMI S. & M S RAJESHWARI & CHANDANI GUPTA & PRESEENT STUDY \\
\hline NORMAL DPA & $56 \%$ & $54.76 \%$ & $91 \%$ & $87 \%$ \\
\hline ABSENT DPA & $2 \%$ & $9.52 \%$ & $3 \%$ & $2.5 \%$ \\
\hline ABSENT AA & $6 \%$ & $16.67 \%$ & $3 \%$ & $10 \%$ \\
\hline
\end{tabular}

Table-2: Comparison of variation in branching pattern of dorsalis pedis artery with the author

\begin{tabular}{|l|l|l|l|}
\hline PARAMETER & M S RAJESHWARI & CHANDANI GUPTA & PRESENT STUDY \\
\hline 3 LATERAL TARSAL ARTERY & $2.38 \%$ & $3 \%$ & $2.5 \%$ \\
\hline 2 LATERAL TARSAL ARTERY & $14.29 \%$ & $0 \%$ & $7.5 \%$ \\
\hline ABSENT ARCUATE ARTERY & $16.67 \%$ & $3 \%$ & $10 \%$ \\
\hline
\end{tabular}

In the present study arcuate artery was absent in $10 \%$ cases. Dilandro et al., [15] revealed $83.3 \%$ absence of arcuate artery, Yamada et al., [10] in his study observed $33 \%$ absence of arcuate artery suggesting that arcuate artery is not the prime source of blood supply to the dorsal metatarsal arteries. They also found lateral tarsal artery provide 2nd 3rd and 4th metatarsal artery in $47.2 \%$ cases. Rajeshwari M S et al., [7] found same branching pattern in $2.38 \%$ cases where three lateral tarsal arteries named proximal, middle and distal lateral tarsal arteries continued over metatarsals as 2nd, 3rd and 4th metatarsal artery. They also found $14.29 \%$ cases where lateral tarsal arteries were two in number, proximal and distal providing dorsal metatarsal arteries. In present study $2.5 \%$ cases with three lateral tarsal arteries and $7.5 \%$ cases with two lateral tarsal arteries were observed.

The importance of above discussed variation of dorsal pedis artery is useful for interventional radiologist, plastic surgeons, traumatological surgeons nowadays. Any abnormality of normal anatomical pattern of origin, branching and anastomosing pattern of dorsalis pedis artery are of key significance in surgical operative procedures. Earlier validation by angiography for any anomaly may avoid unnecessary surgical hazard. Dorsalis pedis artery is used to record peripheral arterial pulsation. Also the myocutaneous flaps based on dorsalis pedis artery are commonly used for reconstructive surgeries [11].

In present time radiologist prefer dorsalis pedis Artery to femoral artery in performing angiographic studies as it is easily approachable with less complication. Heamostasis can be obtained earlier in dorsalis pedis artery [11]. Various kinds of flaps important for distal foot reconstruction based on dorsal metatarsal arteries are still under invention. Knowledge about anatomical variation in dorsal metatarsal arteries can also help to select the artery for pedicle based flap to repair soft tissue defects in distal 1/3 of lower extremity.

\section{CONCLUSION}

Dorsalis pedis arterial pulse is commonly evaluated in physical examination and a weakened or absent pulse could be result of vascular disease. Dorsalis pedis artery pulse can be felt on dorsal surface of foot distal to dorsal most prominence on navicular bone. As observed dorsalis pedis artery is subjected to variations ranging from abnormal course, origin, distribution to complete absence. This must be kept in mind during examining cases of peripheral vascular disease, thrombosis, acute embolism, thrombo-angitis oblitarans, in which pulse is found lost distal to occlusion. Knowledge of branching patterns observed in this study will be of great significance for vascular surgeons as dorsalis pedis artery is essential for flap transfer and will also help in microvascular surgeries such as re-implantations and repairs. This study will be helpful in improving potential for limb salvage.

\section{ACKNOWLEDGMENT}

We extend our sincere gratitude to HOD of Anatomy for granting permission to access cadaveric dissection for conducting present study.

Conflict of interest: None.

\section{REFERENCE}

1. Standing, S. (2008). Gray's anatomy: the anatomical basis of clinical practice. In chapter 6 : smooth muscle and the cardiovascular and lymphatic territories - The Angiosomes 40th ed. 134-135.

2. Cormack, G. C., \& Lamberty, B. G. H. (1986). Cadaver studies correlation between vessel size 
and anatomical territory of cutaneous supply. British Journal Plastic surgery, 39:300-306.

3. Kennedy, L., Maxime, S., Christopher, J. B., \& Chaminda, J. (2008). Dorsalis pedis aneurysm. A case report and review of the literature. The foot and ankle journal. 1(11):1.

4. Sinnatamby, C. S. (1999). Last's anatomy, regional and applied. 10th ed. 139-145.

5. Ali, M. (1996). Dorsalis pedis artery variation and clinical significance. JIMA; 94:417-418.

6. Mara, L., Tuncal, M., \& Celik, T. (1996). Anamolous dorsalis pedis artery surg. Radio anatomy. 6:319-323.

7. Rageshwari, M. S., Roshankumar, B. N., \& Vijay, K. (2013). An anatomical study on Dorsalis pedis artery. International Journal Anat Research, 2:8892.

8. Vijayalakshmi, S., Raghunath, G., \& Shenoy, V. (2011). Anatomical study of Dorsalis Pedis artery and its clinical correlations. Journal of clinical and Diagnostic Research. 5(2):287-290.

9. Sadler, T. W. (1985). In Langman's Medical Embryology, 5th ed. William and Wilkins, 68-69.

10. Yamada, T., Glovicki, P., \& Bower, T. C. (1993). Variations of the arterial anatomy of foot. American Journal of surgery, 166(2):130-135.
11. Vengadesan, B., \& Pushpalatha, K. (2017). An anatomical study on Dorsalis Pedis artery. International journal of science and Research. 6(2):147-149.

12. Chandani, G., Rakesh, K., Vikram, P., \& Sneha, G. K. (2018). Morphometric study of Dorsalis Pedis artery and variation in its branching pattern. International Medical Journal Malasiya, 17(1):1922.

13. Bailleul, J. P., Olivez, P. R., Mestdagh, H., \& Viliette, B. (1984). Desgraphical anatomy of the Dorsalis Pedis Artery of the foot. Bull Association of anatomy (Nancy); (68):15-25.

14. Kesavi, D., Keerti, S., \& Melani, R. S. (2002). Analogous course of Dorsalis Pedis Artery. Anatomical adjuncts. 3:29-31.

15. Dilandro, A. C., Lija, E. C., \& Lepore, F. L. (2001). The prevalence of arcuate artery and a cadaveric study of 72 feet. Journal of American Pediatric Medical Association, 91(6):300-305.

16. Nilesh, K. M., Omar, A. H., Abdul-Ghaffar, H. E., Al-Hashmi, N. A. (2007). Bilateral Absence of the Arcuate artery on the dorsum of foot. Sultan $Q i$ boos University Medical Journal. 7(2). 